\title{
Polyphenols from Salix tetrasperma Impair Virulence and Inhibit Quorum Sensing of Pseudomonas aeruginosa
}

\author{
Islam Mostafa ${ }^{1}\left({ }^{\circ}\right.$, Hisham A. Abbas $^{2}{ }^{(0)}$, Mohamed L. Ashour ${ }^{3}{ }^{(0}$, Abdelaziz Yasri $^{4}{ }^{(0)}$, \\ Assem M. El-Shazly ${ }^{1}$ (D), Michael Wink ${ }^{5, *(\mathbb{D})}$ and Mansour Sobeh ${ }^{4,5, *(\mathbb{D})}$ \\ 1 Department of Pharmacognosy, Faculty of Pharmacy, Zagazig University, Zagazig 44519, Egypt; \\ islam_mostafa_elbaz@yahoo.com (I.M.); assemels2002@yahoo.co.uk (A.M.E.-S.) \\ 2 Department of Microbiology and Immunology, Faculty of Pharmacy, Zagazig University, Zagazig 44519, \\ Egypt; hishamabbas2008@gmail.com \\ 3 Department of Pharmacognosy, Faculty of Pharmacy, Ain Shams University, Cairo 11566, Egypt; \\ ashour@pharma.asu.edu.eg \\ 4 AgroBioSciences Research Division, Mohammed VI Polytechnic University, Lot 660-Hay MoulayRachid, \\ Ben-Guerir 43150, Morocco; aziz.yasri@um6p.ma \\ 5 Institute of Pharmacy and Molecular Biotechnology, Heidelberg University, 69120 Heidelberg, Germany \\ * Correspondence: wink@uni-heidelberg.de (M.W.); mansour.sobeh@um6p.ma (M.S.)
}

Received: 24 February 2020; Accepted: 13 March 2020; Published: 16 March 2020

\begin{abstract}
Bacterial resistance represents one of the emerging obstacles in plants, animals, and humans that impairs treatment with antibacterial agents. Targeting of the bacterial quorum sensing system is one of the strategies to overcome this problem. Recently, research has been focused on natural and food components which can function as quorum sensing inhibitors. In this study, a methanol extract from Salix tetrasperma stem bark was phytochemically profiled by LC-MS analysis. This resulted in the identification of 38 secondary metabolites with (epi)catechin-(epi)catechin, epicatechin, tremulacin, salicortin, and trichocarposide as the major constituents. The extracts of both stem bark and the previously profiled flower of $S$. tetrasperma were tested for anti-quorum sensing activity in a common and widely distributed pathogen Pseudomonas aeruginosa. The natural products inhibited swimming and swarming motilities, as well as proteolytic and hemolytic activities in a dose-dependent manner. Molecular docking of the constituents from both extracts against the quorum sensing controlling systems Lasl/LasR, rhll/rhlR, and PQS/MvfR showed that epicatechin, (epi)catechin-(epi)catechin, $p$-hydroxy benzoyl galloyl glucose, $p$-hydroxy benzoyl protocatechuic acid glucose, and caffeoylmalic acid could be the main active components. This study supports the importance of secondary metabolites, especially polyphenols, as quorum sensing inhibitors.
\end{abstract}

Keywords: Salix tetrasperma; Pseudomonas aeruginosa; plant pathogen; quorum sensing; virulence inhibition; molecular modeling

\section{Introduction}

Pseudomonas aeruginosa is a Gram-negative bacterium, which can infect plants, animals, and humans $[1,2]$. In plants, $P$. aeruginosa can interact with the roots leading to plant death after their colonization via formation of biofilms [3]. In humans, P. aeruginosa infections are associated with diabetic foot, wound, and burn infections [4-6]. Although several antibacterial agents are used to treat such infections, the development of bacterial resistance is considered to be a limiting factor. Thus, alternative ways to treat bacterial infections and overcome bacterial resistance are required. The use of quorum sensing inhibitors represents a new strategy that interferes with what is called virulence factors $[7,8]$. These virulence factors include protease, elastase, hemolysin, and pyocyanin, as well as 
swimming, swarming and twitching motilities, and biofilm formation. They are all under the control of quorum sensing genes and activated when bacterial cell concentrations reach a critical point [9].

In P. aeruginosa, Lasl/LasR, rhll/rhlR, and PQS/MvfR represent quorum sensing systems that are induced by the autoinducers 3-oxododecanoylhomoserine lactone, butanoylhomoserine lactone, and 2-heptyl-3-hydroxy-4-quinolone, respectively $[4,10,11]$. These autoinducers are responsible for bacterial cell communications [12]. They are secreted by bacterial cells and bind to corresponding receptors when their secreting cells have reached a specific number. Binding induces the expression of virulence factor genes and, consequently, bacterial pathogenesis [13].

Phenolic and flavonoid compounds exhibit anti-quorum sensing activity [14,15]. The genus Salix (family Salicaceae) is rich in phenolics, flavonoids, tannins, and saponins [16-18]. The Indian willow, Salix tetrasperma Roxb. is native to South East Asia and India. A recent study reported substantial peripheral and central analgesic, anti-inflammatory, antipyretic activities, and alleviated hyperalgesia and allodynia pain responses associated with neuropathy. These activities were attributed to the presence of 38 secondary metabolites among them rutin, kaempferide 3-O-glucoside, trichocarposide, coumaroylquinic acid, and salicin [19]. Salicin is a precursor of salicylic acid, which inhibits cyclooxygenase I and II (COX I and COX II), important key enzymes in the formation of mediators for pain, fever, and inflammation [18]. A previous investigation of $S$. tetrasperma bark resulted in the identification of $\beta$-sitosterol, $\beta$-sitosterol acetate, $\beta$-sitosterol-O-glucoside, $\beta$-amyrin, friedelin, $3 \beta$-friedelinol, and palmitic acid [20].

In this work, the chemical composition of the methanol extract of $S$. tetrasperma stem bark was comprehensively characterized utilizing LC-MS/MS (Figures S1-S5). We also investigated the activity of stem bark and flower extracts as quorum sensing inhibitors using P. aeruginosa as a model organism. Additionally, a molecular modeling study utilized binding domains of Lasl/LasR, rhll/rhlR, and $\mathrm{PQS} / \mathrm{MvfR}$ to further understand the experimental findings.

\section{Results}

\subsection{Chemical Composition}

Liquid chromatography coupled with mass spectrometry (LC-MS) was utilized in this study to characterize the chemical composition of the stem bark extract. Altogether, 38 secondary metabolites were detected presenting the following four different categories: Phenolic acids, tannins, flavonoids, and fatty acids. (epi)Catechin-(epi)catechin, (epi)catechin, tremulacin, salicortin, and trichocarposide dominated the extract. Figure 1 illustrates the LC-MS profile of the extract and Table 1 describes the tentatively identified compounds in the extract. As for the flower extract, its chemical constituents were previously explored and documented [19]. Rutin, kaempferide 3-O-glucoside, trichocarposide, coumaroylquinic acid, and salicin were the main components in the flower extract among 38 secondary metabolites. A different pattern was observed between the stem bark and the flower extract: Flavonoids and phenolic acids dominated the flower extract, while proanthocyanidins and phenolic acids prevailed in the stem bark extract. In particular, a series of monomers (catechin and its isomer epicatechin and (epi)gallocatechin), dimers ((epi)catechin-(epi)-gallocatechin, (epi)catechin-(epi)catechin), and trimers ((epi)gallocatechin-(epi)catechin-(epi)catechin and (epi)catechin-(epi)catechin-(epi)catechin) were identified only in the bark extract. 


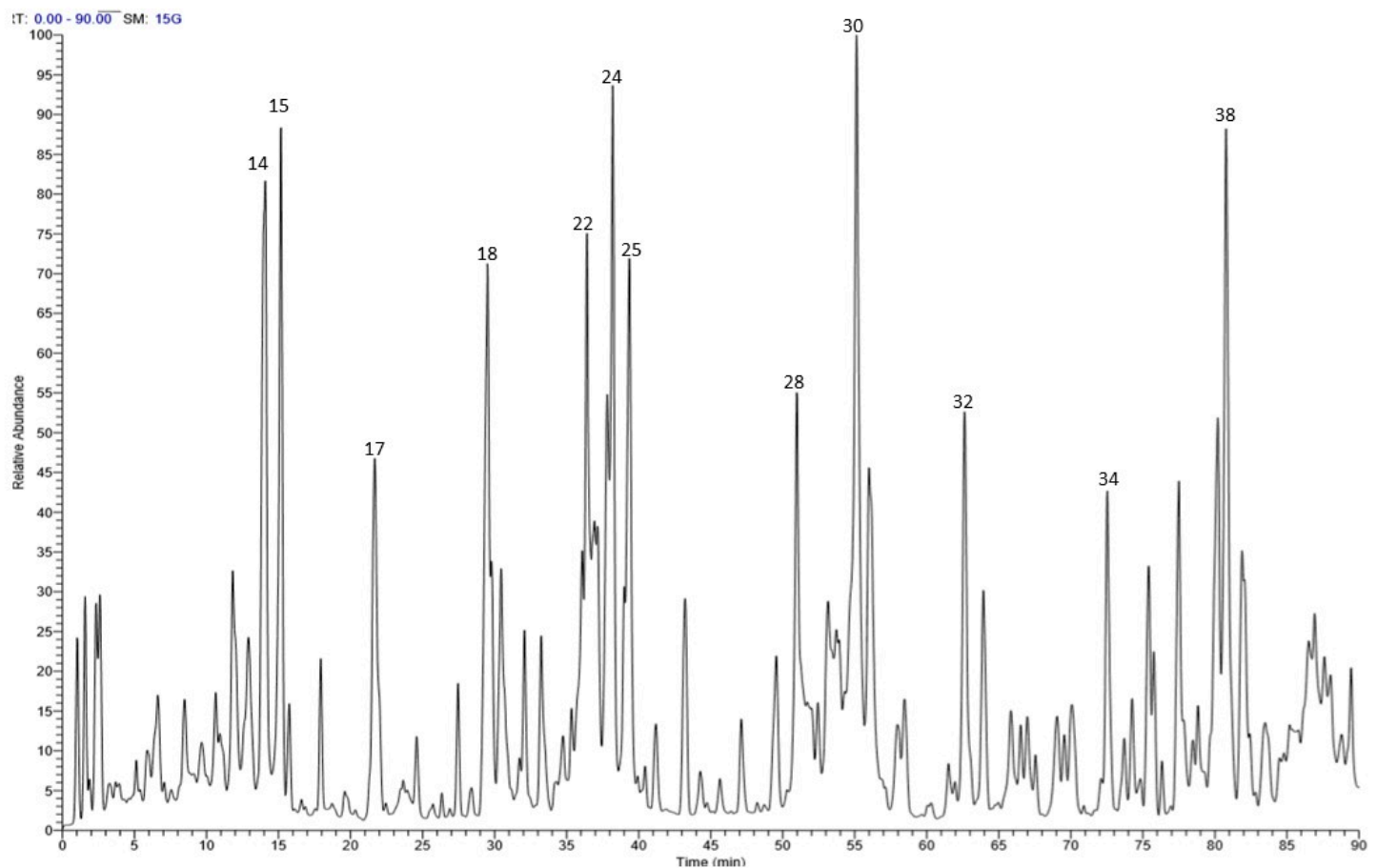

Figure 1. Profile of S. tetrasperma stem bark using LC-MS.

Table 1. Secondary metabolites from S. tetrasperma stem bark.

\begin{tabular}{|c|c|c|c|c|}
\hline No. & RT & M-H $m / z$ & MS/MS & Tentatively Identified Compounds \\
\hline 1 & 0.95 & 507 & $169,345,417$ & Gallic acid glucuronide-glucoside \\
\hline 2 & 1.05 & 133 & - & Malic acid \\
\hline 3 & 1.37 & 191 & 111,173 & Quinic acid \\
\hline 4 & 2.29 & 315 & 153 & Protocatechuic acid 3-O-hexoside * \\
\hline 5 & 2.60 & 331 & $125,169,313$ & Gallic acid glucoside \\
\hline 6 & 2.79 & 447 & 163,315 & Coumaric acid galloyl pentoside \\
\hline 7 & 3.46 & 609 & $305,441,457$ & (epi)Gallocatechin digallate \\
\hline 8 & 5.24 & 593 & $289,425,575$ & (epi)Catechin-(epi)-gallocatechin \\
\hline 9 & 5.91 & 865 & $289,451,595$ & (epi)Catechin-(epi)catechin-(epi)catechin \\
\hline 10 & 6.55 & 609 & $305,423,441$ & (epi)Gallocatechin-(epi)-gallocatechin \\
\hline 11 & 8.46 & 305 & $179,221,287$ & (epi)Gallocatechin \\
\hline 12 & 11.82 & 881 & $289,577,695$ & (epi)Gallocatechin-(epi)catechin-(epi)catechin \\
\hline 13 & 12.81 & 577 & $289,407,451$ & (epi)Catechin-(epi)catechin \# \\
\hline 14 & 13.56 & 577 & $289,407,451$ & (epi)Catechin-(epi)catechin \# \\
\hline 15 & 14.16 & 289 & $179,285,245$ & Epicatechin \\
\hline 16 & 15.12 & 289 & $179,285,245$ & Catechin \# \\
\hline 17 & 21.73 & 423 & 161,285 & Salicortin * \\
\hline 18 & 29.58 & 451 & $169,313,331$ & $p$-Hydroxy benzoyl galloyl glucose \\
\hline 19 & 30.45 & 435 & $153,297,315$ & p-Hydroxy benzoyl protocatechuic acid glucose \\
\hline 20 & 32.07 & 423 & $145,163,307$ & Grandidentatin \# \\
\hline 21 & 33.26 & 423 & $145,163,307$ & Grandidentatin isomer \\
\hline 22 & 36.41 & 477 & $151,179,315$ & Isorhamnetin-3-O-glucoside \\
\hline 23 & 37.82 & 431 & $145,163,307$ & Trichocarposide * \\
\hline 24 & 38.19 & 431 & $145,163,307$ & Trichocarposide isomer \\
\hline 25 & 39.33 & 431 & $145,163,307$ & Trichocarposide isomer \\
\hline 26 & 43.23 & 435 & 179,273 & Phlorizin \\
\hline 27 & 49.29 & 569 & $307,423,431$ & Coumaroyl dihydrobenzoylsalicin * \\
\hline 28 & 5.92 & 631 & $191,329,353$ & Chlorogenic acid derivative \\
\hline 29 & 53.02 & 569 & $307,423,431$ & Coumaroyl dihydrobenzoylsalicin isomer * \\
\hline 30 & 55.21 & 527 & 155,405 & Tremulacin * \\
\hline 31 & 56.32 & 577 & 269 & Terniflorin * \\
\hline 32 & 62.93 & 309 & $171,251,291$ & Fatty acid derivative \\
\hline 33 & 70.32 & 311 & 293,311 & Eicosanoic acid \\
\hline 34 & 72.48 & 723 & $269,453,559,577$ & Coumaroyl-terniflorin \\
\hline 35 & 75.53 & 271 & $209,253,271$ & Unidentified \\
\hline 36 & 77.26 & 293 & $171,235,275,293$ & Hydroxy-octadecatrienoic acid * \\
\hline 37 & 79.92 & 295 & $171,277,295$ & Hydroxy-octadecadienoic acid * \\
\hline 38 & 81.01 & 295 & $171,277,295$ & Hydroxy-octadecadienoic acid isomer \\
\hline 39 & 82.39 & 293 & $113,249,293$ & Hydroxy-octadecatrienoic acid isomer \\
\hline
\end{tabular}

* previously described in the flower extract [19] and ${ }^{\#}$ previously described in Salix subserata [21]. 
Compound 18, retention time $29.58 \mathrm{~min}$, exhibited a $[\mathrm{M}-\mathrm{H}]^{-}$at $m / z 451$ and three daughter ions at $m / z 169$ [M-H-120-162], 313 [M-H-120-18], 331 [M-H-120], was characterized as $p$-hydroxy benzoyl galloyl glucose (Figure 2a,b). Compound 19, retention time $30.45 \mathrm{~min}$, demonstrated a [M $\mathrm{H}]^{-}$at $m / z 435$ and three fragments at $m / z 153$ [M-H-120-162], 297 [M-H-120-18], 315 [M-H-120], was identified as $p$-hydroxy benzoyl protocatechuic acid glucose (Figure $3 \mathrm{a}, \mathrm{b}$ ).

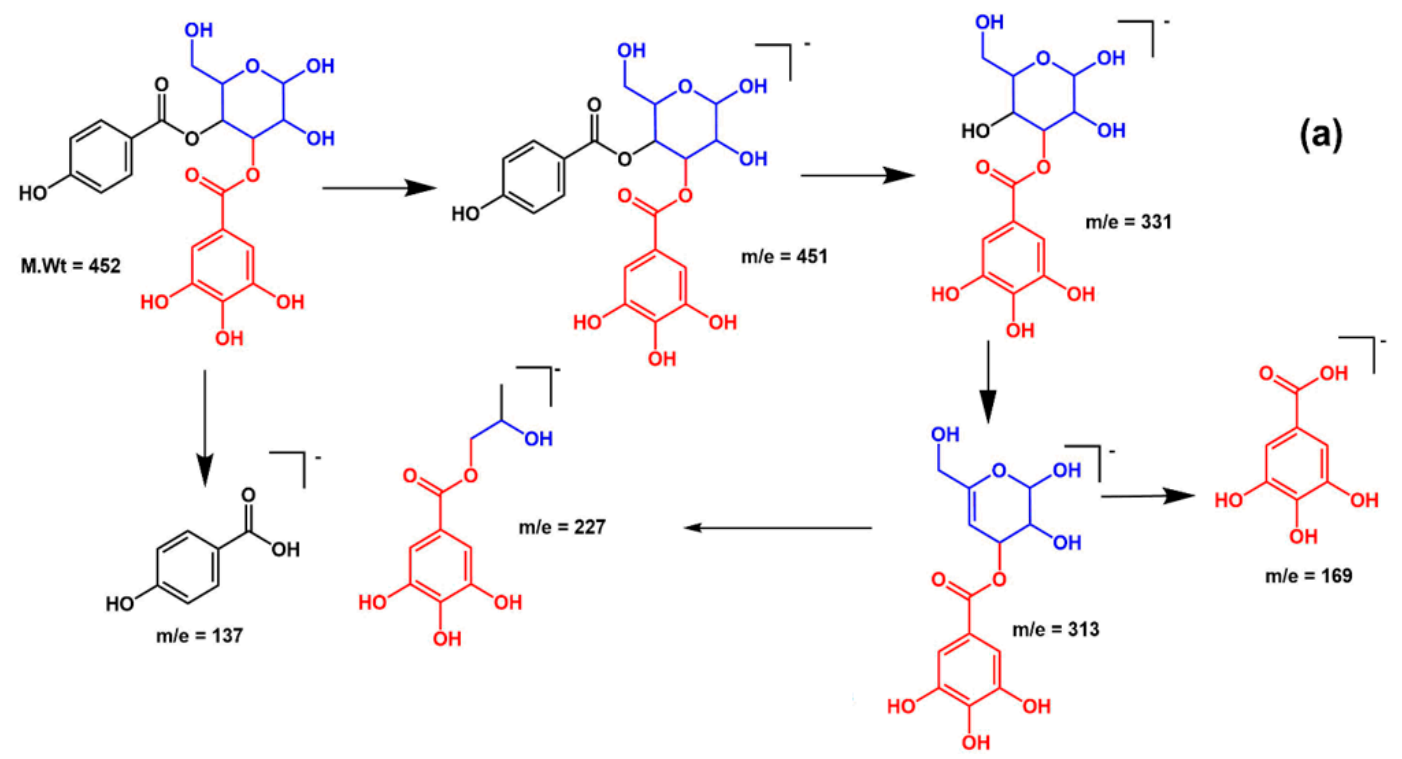

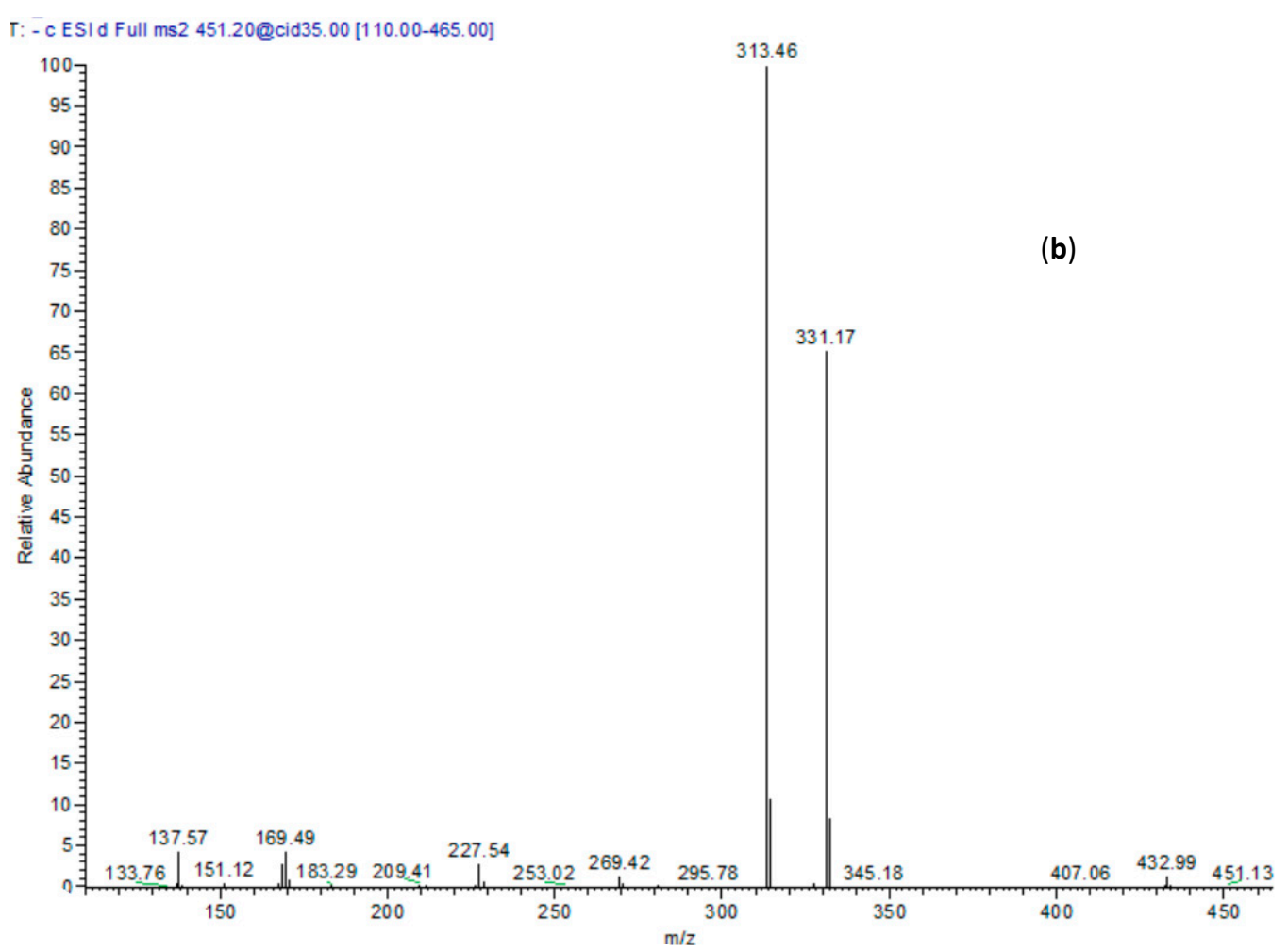

Figure 2. (a) A proposed fragmentation pattern of $p$-hydroxy benzoyl galloyl glucose at $[\mathrm{M}-\mathrm{H}]^{-} \mathrm{m} / \mathrm{z}$ $451 ;$ (b) Recorded spectra $\left(\mathrm{MS}^{2}\right.$ ) by ESI negative ion mode. 

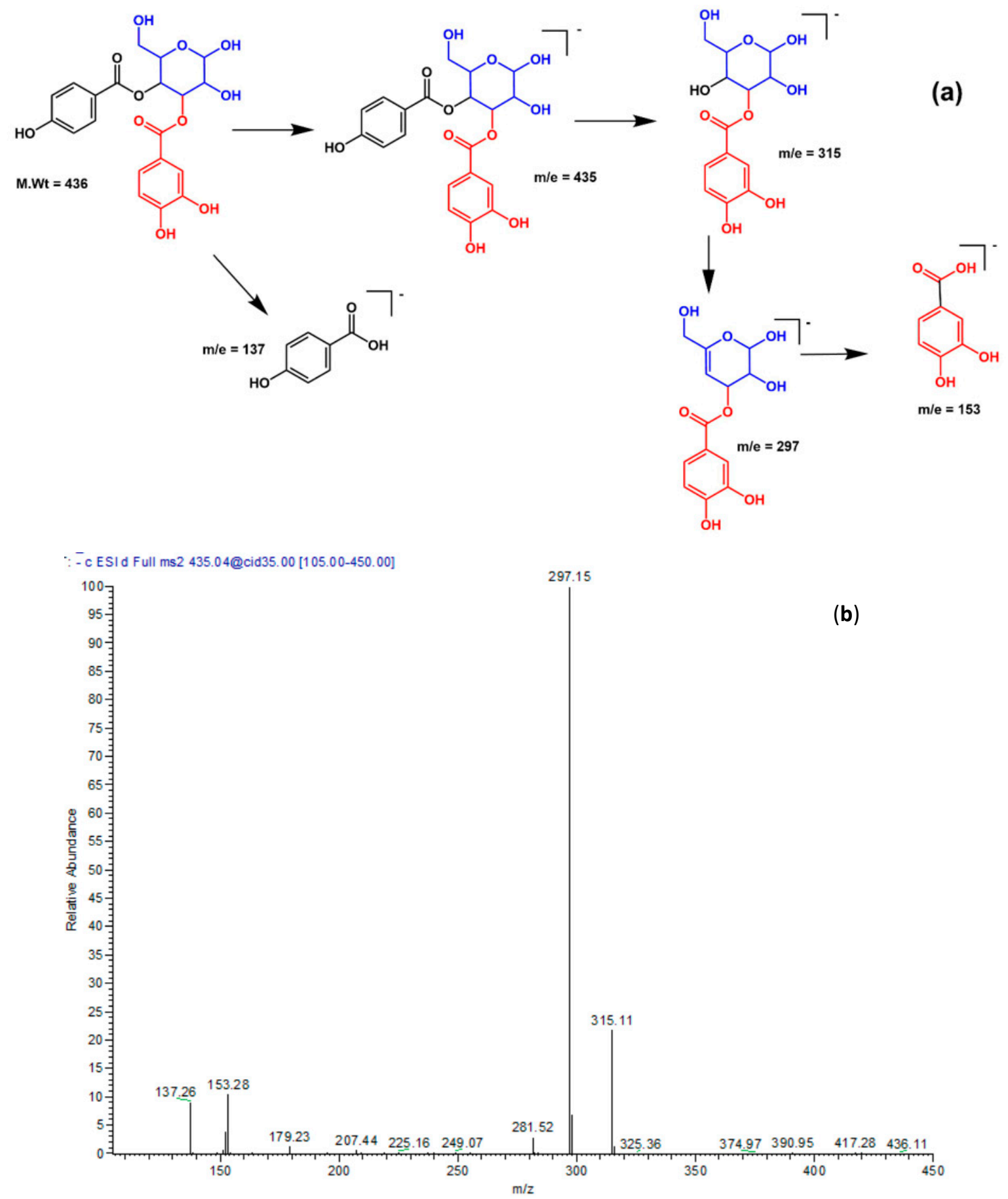

Figure 3. (a) A proposed fragmentation pattern of $p$-hydroxy benzoyl protocatechuic acid glucose at $[\mathrm{M}-\mathrm{H}]^{-} \mathrm{m} / \mathrm{z} 435$; (b) Recorded spectra $\left(\mathrm{MS}^{2}\right)$ by ESI negative ion mode.

\subsection{Antibacterial Activities}

Salix tetrasperma stem bark and flower extracts inhibited P. aeruginosa PAO1 growth at a concentration of $40 \mathrm{mg} / \mathrm{mL}$. In order to evaluate their effects as quorum sensing inhibitors, doses of 10 and $5 \mathrm{mg} / \mathrm{mL}$ representing $1 / 4$ and $1 / 8$ MIC were used. To ensure that these concentrations had no effect on PAO1 growth, the bacterial cells were allowed to grow overnight in LB broth in the presence and absence of $1 / 4$ and $1 / 8$ MIC of the investigated extracts and the absorbance of suspension culture was measured at $600 \mathrm{~nm}$. The statistical calculations indicated no significant difference in growth in 
the presence and absence of $1 / 4$ and $1 / 8 \mathrm{MIC}$ of the investigated extracts, indicating that any activity could be attributed to quorum sensing but not bacterial growth inhibition.

\subsection{Stem Bark and Flower Extracts as Biofilm Inhibitors}

To investigate the anti-biofilm effect, biofilm formation took place in the presence and absence of the different extracts on sterile cover slips, the formed biofilms were stained with crystal violet and examined under microscope. The treated PAO1 showed scattered cells pattern in a dose-dependent manner (lower than MIC) relative to control (Figure 4).

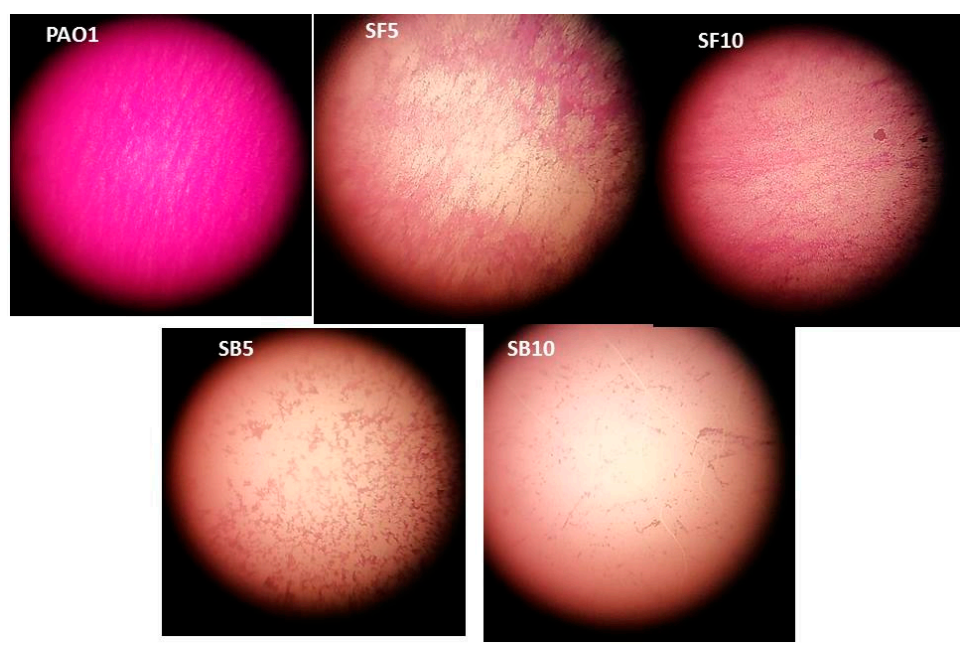

Figure 4. Biofilm inhibition using $S$. tetrasperma stem bark and flower extracts. PAO1, P. aergunosa strain; SB5, stem bark extract $(5 \mathrm{mg} / \mathrm{mL})$; SB10, stem bark extract $(10 \mathrm{mg} / \mathrm{mL})$; SF5, flower extract (5 $\mathrm{mg} / \mathrm{mL})$; SF10, flower extract $(10 \mathrm{mg} / \mathrm{mL})$. Biofilm was stained with crystal violet and visualized under light microscope $(\times 1000)$.

\subsection{Effect on Swimming and Swarming Motilities}

PAO1 motility impairment was achieved using $S$. tetrasperma stem bark and flower extracts. The extracts reduced swimming motility to $32.76 \%$ and $39.66 \%$ at a concentration of $5 \mathrm{mg} / \mathrm{mL}$ and to $85.63 \%$ and $74.14 \%$ at a concentration of $10 \mathrm{mg} / \mathrm{mL}$ (Figure $5 \mathrm{a}$ ). The swarming motility was decreased to $21.74 \%$ and $3.91 \%$ at a $5 \mathrm{mg} / \mathrm{mL}$ concentration of the stem bark and flower extracts, and to $43.47 \%$ and $56.96 \%$ at a $10 \mathrm{mg} / \mathrm{mL}$ concentration of the same extracts (Figure $5 \mathrm{~b}$ ).
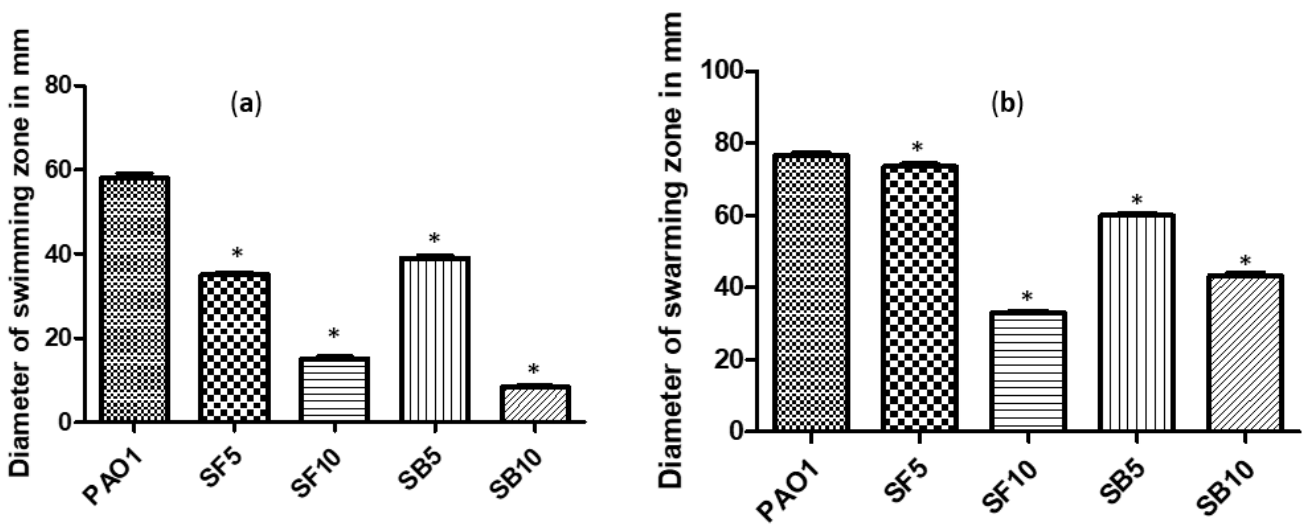

Figure 5. (a) Swimming motility inhibition by S. tetrasperma stem bark and flower extracts; (b) Swarming motility inhibition by stem bark and flower extracts. PAO1, P. aergunosa strain; SB5, stem bark extract (5 mg/mL); SB10, stem bark extract $(10 \mathrm{mg} / \mathrm{mL})$; SF5, flower extract $(5 \mathrm{mg} / \mathrm{mL})$; SF10, flower extract $(10 \mathrm{mg} / \mathrm{mL}) . \mathrm{n}=3$; $^{*}$ significant change at ${ }^{*} p<0.05$. 


\subsection{Inhibition of Protease Production and Hemolytic Activity}

The supernatant of PAO1 cultures treated with $5 \mathrm{mg} / \mathrm{mL}$ and $10 \mathrm{mg} / \mathrm{mL}$ of the stem bark extract inhibited protease production completely at both concentrations. Treatment of PAO1 culture with the flower extract reduced protease production as indicated by reduction in proteolytic activity to values of $17.43 \%$ and $52.28 \%$ at concentrations of 5 and $10 \mathrm{mg} / \mathrm{mL}$, respectively (Figure 6 ). The activity was calculated by measurement of the clearance zone around the wells containing the tested extracts in skim milk agar. The PAO1 treated cultures showed reduction in hemolytic activity by $54.65 \%$ and $71.79 \%$ as compared with untreated ones using $5 \mathrm{mg} / \mathrm{mL}$ of stem bark and flower extracts, respectively. Increasing the stem bark and flower extracts concentration to $10 \mathrm{mg} / \mathrm{mL}$ resulted in a decline of hemolytic activity to $97.76 \%$ and $91.36 \%$, respectively. This was clear from spectrophotometric assay of the hemoglobin released from the cultures' supernatant (Figure 7).

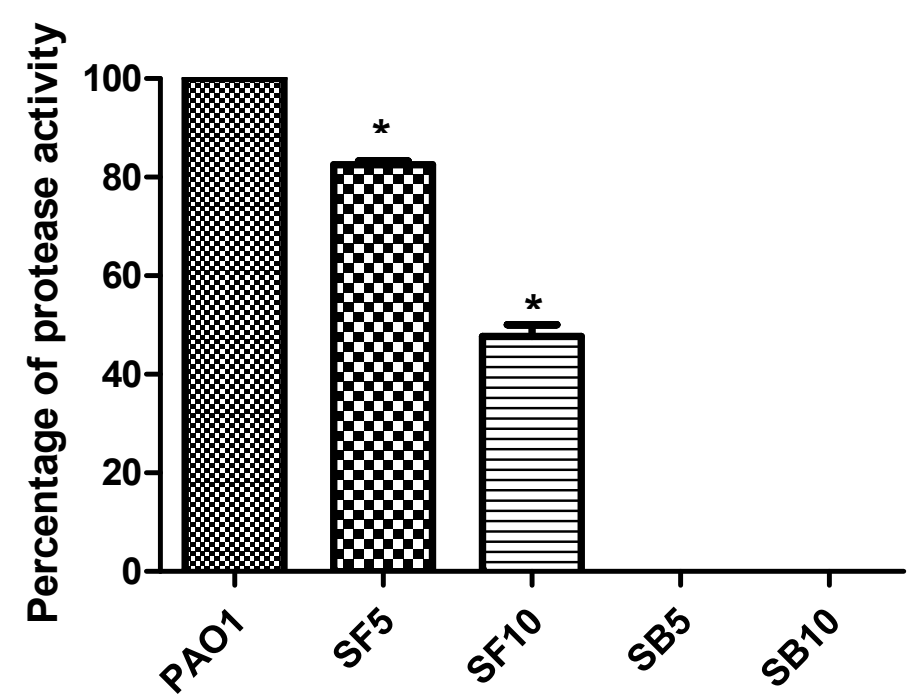

Figure 6. Protease production inhibition by $S$. tetrasperma stem bark and flower extracts using skim milk agar method. PAO1, P. aergunosa strain; SB5, stem bark extract ( $5 \mathrm{mg} / \mathrm{mL})$; SB10, stem bark extract $(10 \mathrm{mg} / \mathrm{mL})$; SF5, flower extract $(5 \mathrm{mg} / \mathrm{mL}) ; \mathrm{SF} 10$, flower extract $(10 \mathrm{mg} / \mathrm{mL}) . \mathrm{n}=3$; ${ }^{*}$ significant change at $*<0.05$.

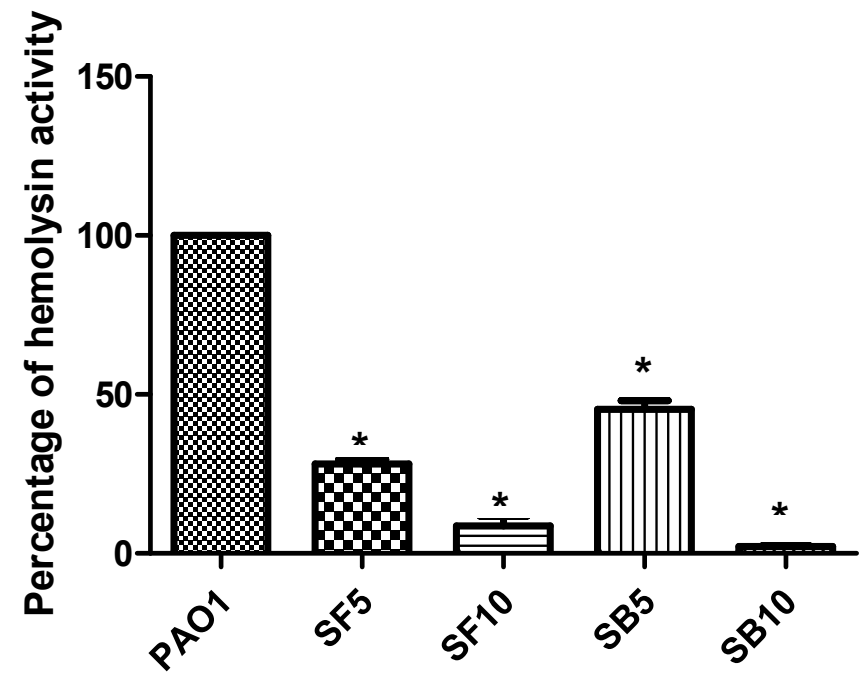

Figure 7. Hemolytic activity inhibition by S. tetrasperma stem bark and flower extracts. PAO1: P. aergunosa strain; SB5, stem bark extract ( $5 \mathrm{mg} / \mathrm{mL})$; SB10, stem bark extract $(10 \mathrm{mg} / \mathrm{mL})$; SF5, flower extract $(5 \mathrm{mg} / \mathrm{mL}) ; \mathrm{SF} 10$, flower extract $(10 \mathrm{mg} / \mathrm{mL}) . \mathrm{n}=3 ;{ }^{*}$ significant change at ${ }^{*} p<0.05$. 


\subsection{Molecular Modeling}

To gain insight about the molecular mechanism of action of the studied extracts, an in silico study was conducted using the identified secondary metabolites from the active extracts on P. aeruginosa LasR ligand-binding domain, RhlG/NADP active site, and PqsR active domain, which are the main systems controlling the biofilm formation. Among the docked compounds in the active site of P. aeruginosa LasR ligand-binding domain, only caffeoylmalic acid showed the highest fitting score within the active sites with $\Delta G$ equals to $-41.66 \mathrm{kcal} / \mathrm{mol}$, which is close to the enzyme ligand interaction value $(\Delta G=-59.94$ $\mathrm{kcal} / \mathrm{mol}$ ). As seen from the amino acid interactions at the enzyme pocket, caffeoylmalic acid forms a lot of favorable interactions with the amino acid residues at the active sites evidenced by the formation of three $\pi$-bonds with ASP E:73 and ARG E:61. Additionally, two conventional hydrogen bonds are formed between the polar oxygen atoms existing in the hydroxyl and carbonyl moieties and the amino acid residues TRP E:88 and ARG E:61. In addition, van der Waals interaction exists between the carbonyl group of the compound and the amino acid residue GLY E:38 and TYR E:64; both catechin and epicatechin showed close binding energies after docking with different interaction mode; both formed a $\pi$-bond with ASP E:73 residue beside four hydrogen bonds between the phenolic $\mathrm{OH}$ groups and the amino acid residues ARG E:61, SER E:129, THR E:75, and LEU E:125. Other compounds failed to dock or docked but showed unfavorable interaction manifested by the positive values of the free binding energies. It is worthwhile to mention that, in the rule-based method, the phenolic groups dissociate to the negatively charged phenolate groups. These phenolate species can form a firm binding at the active sites via ionic bonding and p-bond with the amino acid residues at the active sites.

Similar results were noticed in the docking of compounds in the active site of rhll/rhlR system of $P$. aeruginosa. Cacffeoylmalic acid revealed the strongest affinity to the enzyme as seen in the high fitting score $(-74.39 \mathrm{kcal} / \mathrm{mol})$ that even exceeded the binding energy of the co-crystallized ligand itself $(-71.47 \mathrm{kcal} / \mathrm{mol})$ and similar binding interaction with the amino acid residues ARG A:19, ARG A:41, ASP A:42, ASN A:92, SER A:18, and GLY A:16. It is worthwhile mentioning that $p$-hydroxy benzoyl galloyl glucose and $p$-hydroxy benzoyl protocatechuic acid glucose showed binding energies $(\Delta G=-33.82,30.41 \mathrm{kcal} / \mathrm{mol}$, respectively), which are closely related to the values of catechin and epicatechin. The interactions of epicatechin involved the formation of hydrogen bonds with ARG A:19, ASN A:92, GLY A:16, GLY A:22, GLY A:147, ILE A:21, and LYS A:166 residues. These strong ionic bonds are attributed to the dissociation of the phenolic groups at the physiological fluid and interacting with amino residues at the active site. Other compounds showed weaker interactions as indicated by the low binding energies (Table 2 and Figures 8-10).

However, the docking results on P. aeruginosa quorum sensing regulator PQS/MvfR system revealed a different pattern. (epi)Catechin-(epi)catechin showed the highest fitting score with binding energy equal to $\Delta G=-36.51 \mathrm{kcal} / \mathrm{mol}$ that is close to that of the co-crystalline ligand $(\Delta G=-36.14 \mathrm{kcal} / \mathrm{mol}$ ). The binding involved the formation of a strong three hydrogen bonds with ARG: 209, LEU: 208, and ASP: 264 that could be explained in relation with the dissociation of the phenolic groups in the catechin and weak van der Waals bonds with THR: 265, ASN: 206, and LEU: 207. Caffeoylmalic acid, catechin. epicatechin, $p$-hydroxy benzoyl galloyl glucose, and $p$-hydroxy benzoyl protocatechuic acid glucose showed binding energies ranging from -33.62 to $-26.13 \mathrm{kcal} / \mathrm{mol}$ and the binding amino acids involved were TYR:258, LEU:197, and SER:196 (Table 2 and Figures 8-10). 

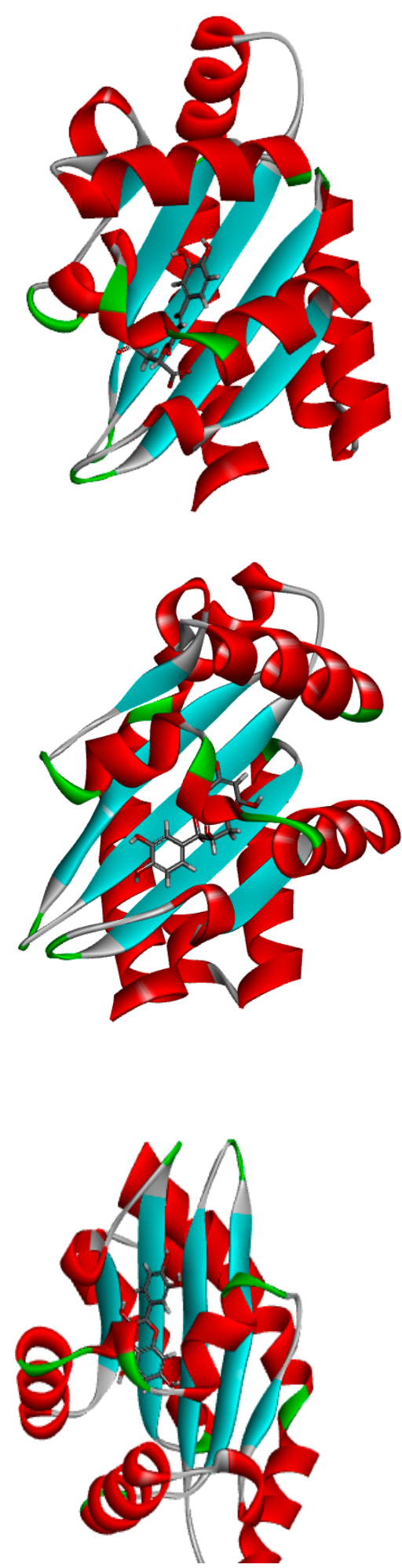
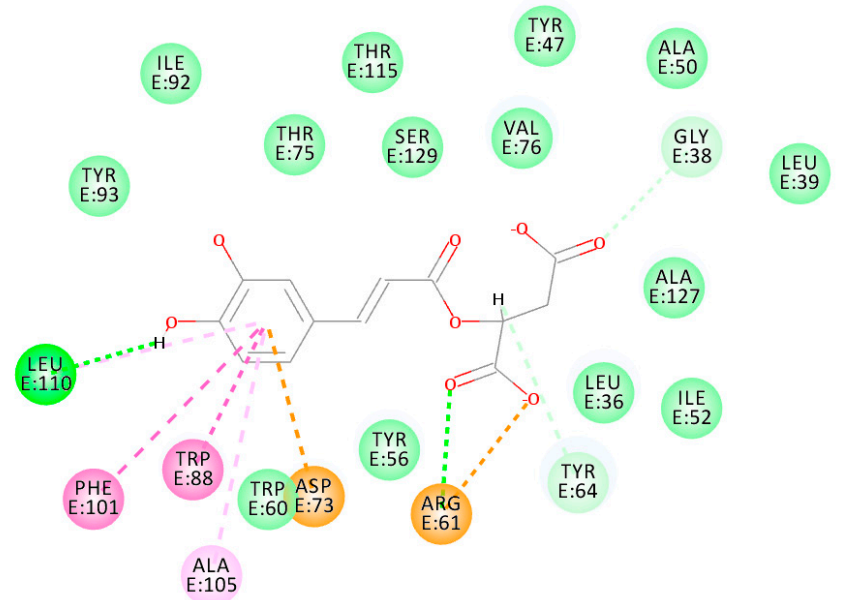

E:105
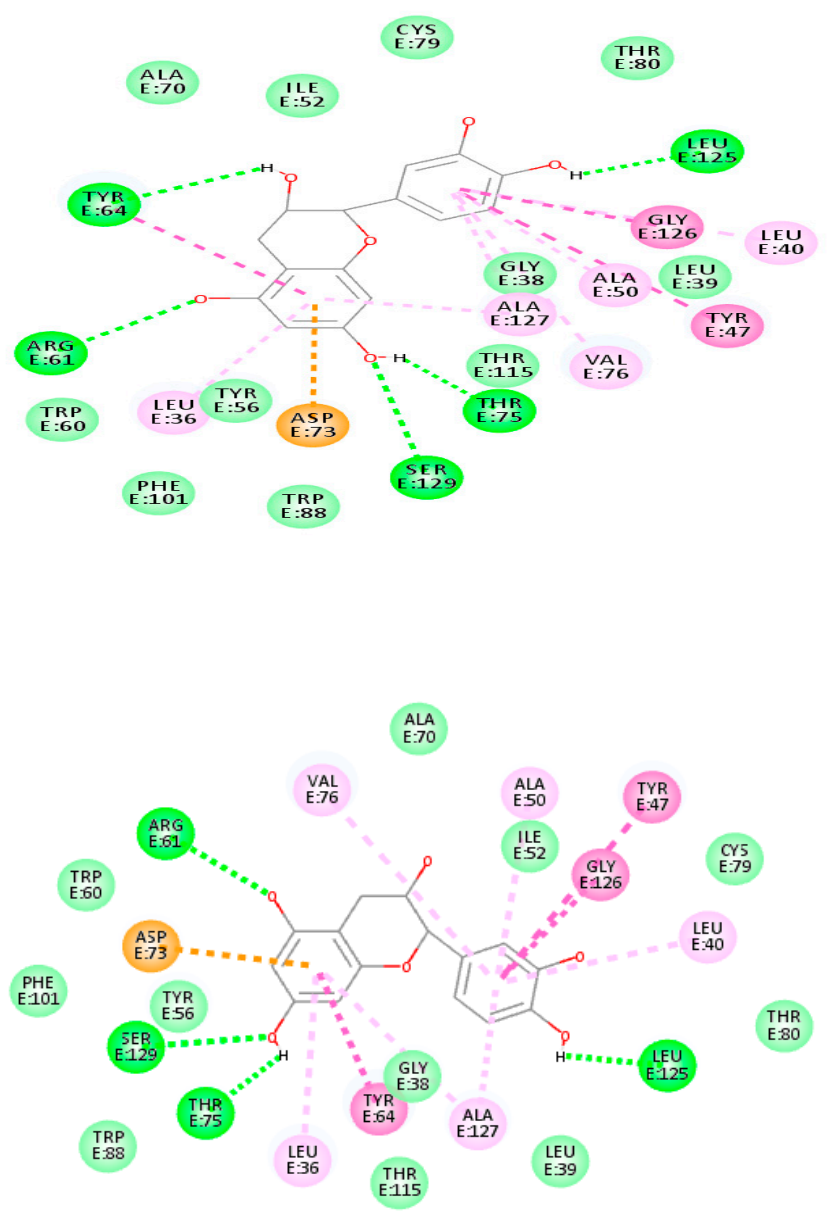

Figure 8. Two-dimensional (2D) (right) and three-dimensional (3D) (left) binding modes of caffeoylmalic acid (top), epicatechin (middle), and catechin (bottom) in the LasR ligand-binding domain of P. aeruginosa using rule-based ionization mode. 

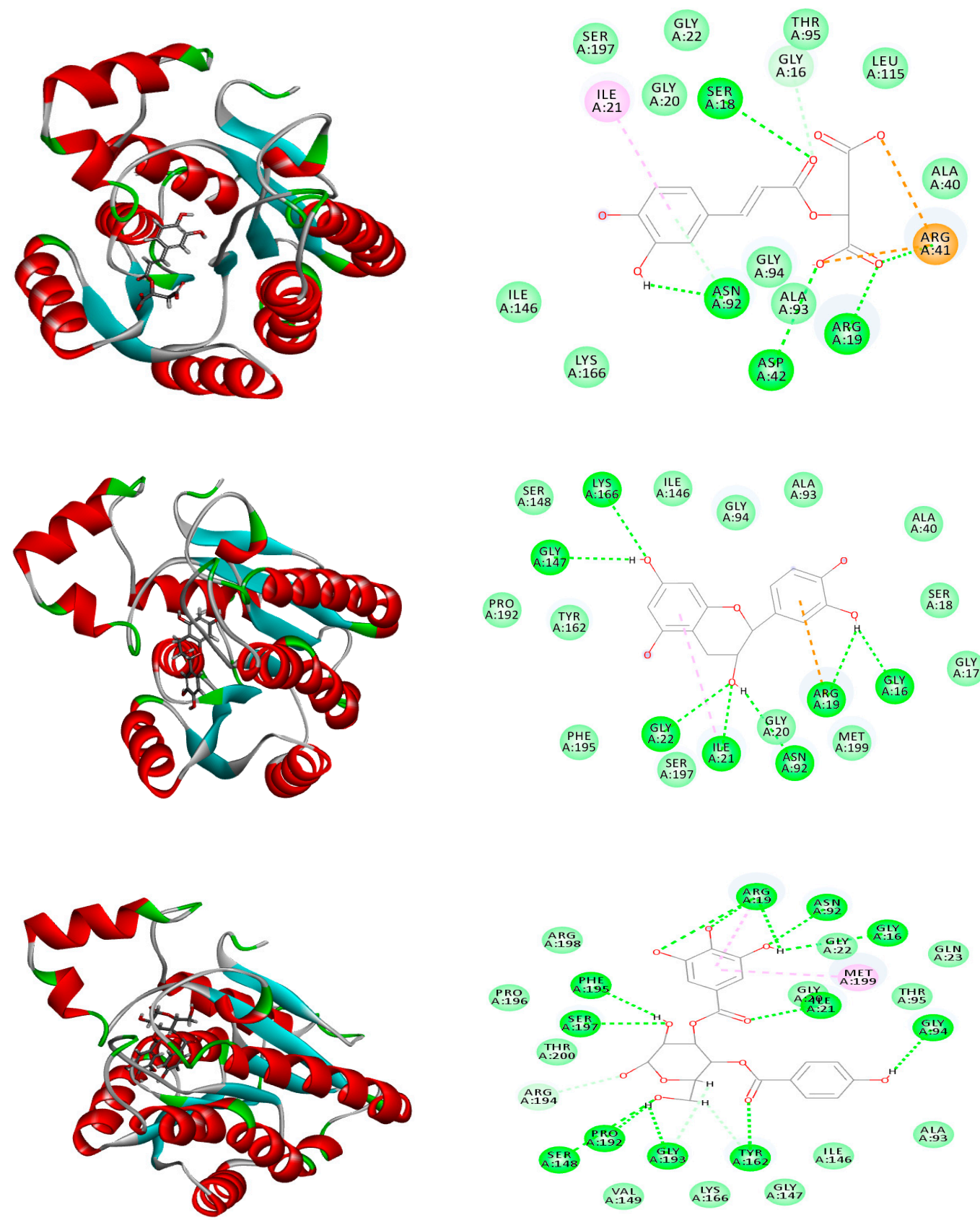

Figure 9. 2D (right) and 3D (left) binding modes of caffeoylmalic acid (top), epicatechin (middle), and p-hydroxy benzoyl galloyl glucose (bottom) in the rhll/rhlR system of P. aeruginosa using rule-based ionization mode. 

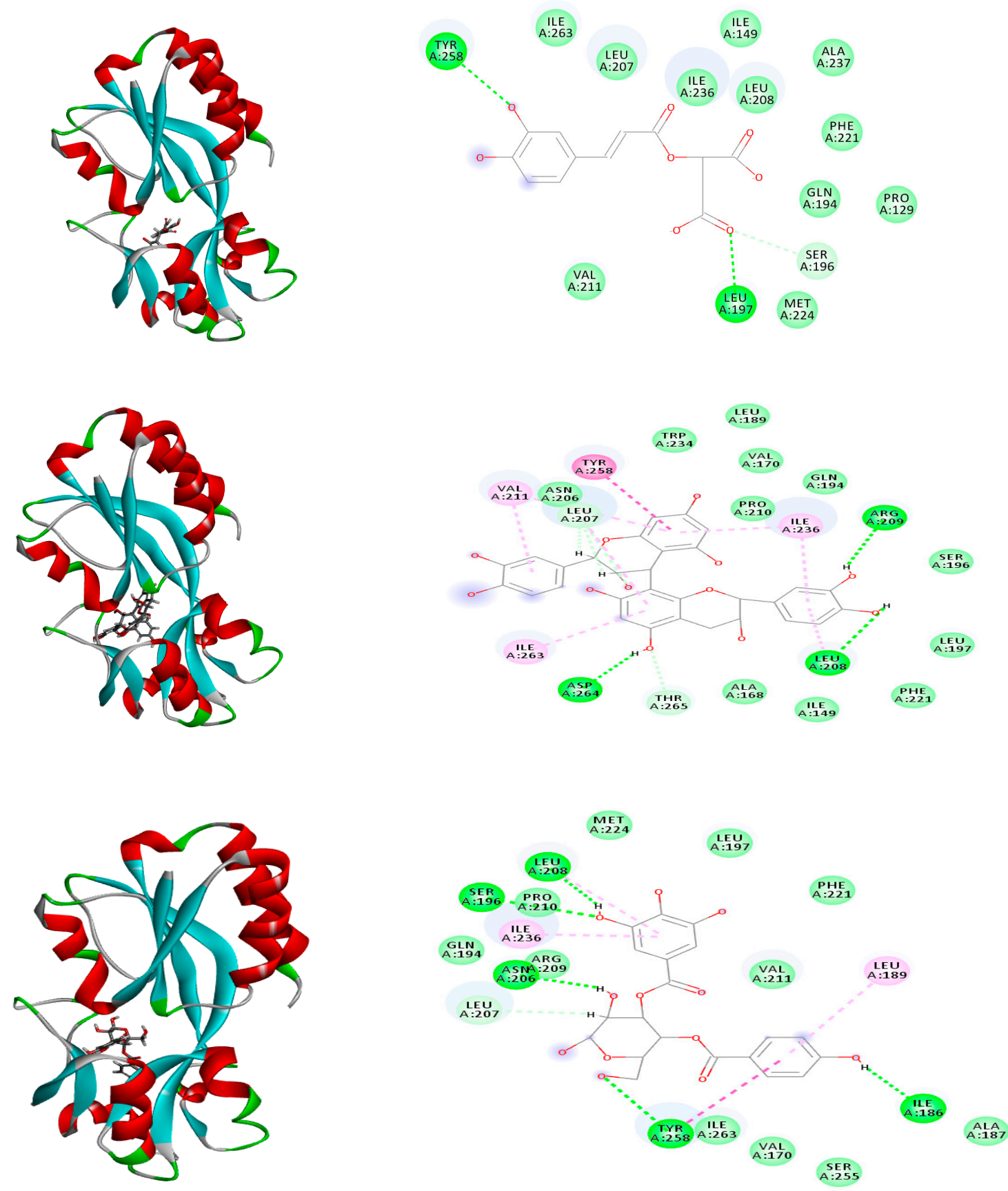

Figure 10. 2D (right) and 3D (left) binding modes of caffeoylmalic acid (top), (epi)catechin-(epi)catechin (middle), and $p$-hydroxy benzoyl galloyl glucose (bottom) in P. aeruginosa quorum sensing regulator PqsR/MvfR system using rule-based ionization mode. 
Table 2. Free binding energies $(\mathrm{kcal} / \mathrm{mol})$ and the amino acid interaction of the identified compounds from $S$. tetrasperma stem bark and flower extracts in the active sites of Lasl/LasR system, rhll/rhlR system, and PQS/MvfR system using virtual screening program.

\begin{tabular}{|c|c|c|c|c|c|c|}
\hline \multirow[b]{2}{*}{ Compound Name } & \multicolumn{2}{|c|}{ 2UV0 Protein } & \multicolumn{2}{|c|}{ 2B4Q Protein } & \multicolumn{2}{|c|}{ 4JVD Protein } \\
\hline & Free Binding Energy & $\begin{array}{l}\text { Amino Acid } \\
\text { Interactions }\end{array}$ & Free Binding Energy & $\begin{array}{l}\text { Amino Acid } \\
\text { Interactions }\end{array}$ & Free Binding Energy & $\begin{array}{l}\text { Amino Acid } \\
\text { Interactions }\end{array}$ \\
\hline Caffeoylmalic acid & -41.66 & $\begin{array}{c}\text { ASP E:73, } \\
\text { ARG E:61, } \\
\text { LEU E:110, } \\
\text { TRP E:88, } \\
\text { ALA E:105 }\end{array}$ & -74.39 & $\begin{array}{l}\text { ARG A:41, } \\
\text { ARG A:19, } \\
\text { ASP A:42, } \\
\text { ASN A:92, } \\
\text { SER A:18, } \\
\text { GLY A:16 }\end{array}$ & -30.09 & $\begin{array}{l}\text { TYR:258, } \\
\text { LEU: 197, } \\
\text { SER:196 }\end{array}$ \\
\hline Kaempferol-3-O-galactoside & Unfavorable binding & - & -1.82 & $\begin{array}{c}\text { GLY A:94, } \\
\text { ASN A:92, } \\
\text { ARG A:19, } \\
\text { MET A:199, } \\
\text { ALA A:93, } \\
\text { SER A:18 }\end{array}$ & -4.19 & $\begin{array}{l}\text { ARG A: } 209, \\
\text { ASP A: } 264, \\
\text { GLN A: } 194, \\
\text { PRO A: } 210\end{array}$ \\
\hline Kaempferide-3-O-glucoside & Unfavorable binding & - & Unfavorable binding & - & -3.46 & $\begin{array}{l}\text { TYR A: } 258, \\
\text { LEU A: } 197, \\
\text { LEU A: 208, } \\
\text { GLN A: } 194 \\
\text { SER A: } 196, \\
\text { ARG A: } 209\end{array}$ \\
\hline (epi)Catechin-(epi)catechin & FD & - & FD & - & -36.51 & $\begin{array}{l}\text { ARG A: 209, } \\
\text { LEU A: 208, } \\
\text { ASP A: 264, } \\
\text { THR A: 265, } \\
\text { ASN A: 206, } \\
\text { LEU A: } 207\end{array}$ \\
\hline Epicatechin & -39.23 & $\begin{array}{l}\text { ASP E:73, } \\
\text { SER E:129, } \\
\text { THR E:75, } \\
\text { LEU E:125 }\end{array}$ & -37.91 & $\begin{array}{c}\text { ARG A:19, } \\
\text { GLY A:16, } \\
\text { GLY A:22, } \\
\text { GLY A:147, } \\
\text { ASN A:92, } \\
\text { ILE A:21, } \\
\text { LYS A:166 }\end{array}$ & -26.83 & $\begin{array}{l}\text { ILE A: } 236, \\
\text { ASP A: } 264, \\
\text { LEU A: } 207\end{array}$ \\
\hline Catechin & -36.66 & $\begin{array}{c}\text { ARG E:61, } \\
\text { SER E: } 129, \\
\text { THR E:75, } \\
\text { LEU E:125 }\end{array}$ & -35.51 & $\begin{array}{l}\text { ARG A:19, } \\
\text { GLY A:94, } \\
\text { ASN A:92, } \\
\text { GLY A:147, } \\
\text { GLY A:193, } \\
\text { SER A:148 }\end{array}$ & -26.13 & $\begin{array}{l}\text { TYR A: } 258, \\
\text { LEU A: } 208 \\
\text { LEU A: } 207\end{array}$ \\
\hline Tremulacin & FD & - & -12.67 & $\begin{array}{c}\text { ARG A:19, } \\
\text { ASN A:92, } \\
\text { MET A:199, } \\
\text { PHE A:195, } \\
\text { SER A:197, } \\
\text { GLY A:20, } \\
\text { TYR A:162 }\end{array}$ & -6.83 & $\begin{array}{l}\text { TYR A: 258, } \\
\text { LEU A: 207, } \\
\text { LEU A: 208, } \\
\text { SER A: 196, } \\
\text { LEU A: } 207\end{array}$ \\
\hline
\end{tabular}


Table 2. Cont.

\begin{tabular}{|c|c|c|c|c|c|c|}
\hline \multirow[b]{2}{*}{ Compound Name } & \multicolumn{2}{|c|}{ 2UV0 Protein } & \multicolumn{2}{|c|}{ 2B4Q Protein } & \multicolumn{2}{|c|}{ 4JVD Protein } \\
\hline & Free Binding Energy & $\begin{array}{l}\text { Amino Acid } \\
\text { Interactions }\end{array}$ & Free Binding Energy & $\begin{array}{l}\text { Amino Acid } \\
\text { Interactions }\end{array}$ & Free Binding Energy & $\begin{array}{l}\text { Amino Acid } \\
\text { Interactions }\end{array}$ \\
\hline Trichocarposide & Unfavorable binding & - & -15.87 & $\begin{array}{c}\text { ARG A:19, } \\
\text { ARG A:41, } \\
\text { ASN A:92, } \\
\text { MET A:199, } \\
\text { TYR A:162, } \\
\text { GLY A:147, } \\
\text { SER A:197 }\end{array}$ & -12.63 & $\begin{array}{l}\text { ILE A:186, } \\
\text { LEU A: } 207\end{array}$ \\
\hline $\begin{array}{l}p \text {-Hydroxy benzoyl galloyl } \\
\text { glucose }\end{array}$ & Unfavorable binding & - & -33.82 & $\begin{array}{c}\text { ARG A:19, } \\
\text { GLY A:16, } \\
\text { GLY A:22, } \\
\text { SER A:197, } \\
\text { ILE A:21, } \\
\text { TYR A:162, } \\
\text { GLY A:94, } \\
\text { PHE A:195, } \\
\text { ASN A:92 }\end{array}$ & -33.62 & $\begin{array}{l}\text { ILE A: } 186, \\
\text { TYR A: } 258, \\
\text { ASN A: } 206, \\
\text { LEU A: 208, } \\
\text { SER A: } 196, \\
\text { LEU A: } 207\end{array}$ \\
\hline $\begin{array}{c}p \text {-Hydroxy benzoyl } \\
\text { protocatechuic acid glucose }\end{array}$ & Unfavorable binding & - & -30.41 & $\begin{array}{l}\text { ARG A:19, } \\
\text { GLY A:16, } \\
\text { GLY A:22, } \\
\text { GLY A:147, } \\
\text { ILE A:21, } \\
\text { LYS A:164, } \\
\text { GLY A:94, }\end{array}$ & -28.96 & $\begin{array}{l}\text { ILE A: } 186, \\
\text { TYR A: } 258, \\
\text { GLN A: } 151, \\
\text { LEU A: } 207\end{array}$ \\
\hline
\end{tabular}

FD, fail to dock.

\section{Discussion}

In this work, we comprehensively characterized the chemical constituents of S. tetrasperma stem bark extract using LC-MS and 38 secondary metabolites were detected. Eight compounds have been identified before from the flower extract including salicortin, trichocarposide, coumaroyl dihydrobenzoylsalicin and its isomer, tremulacin, terniflorin, hydroxy-octadecatrienoic acid, and hydroxy-octadecadienoic acid [19].

The increase of antibiotic resistance presents a limiting factor in the treatment of bacterial infection. Many trials have been developed to overcome this problem from which quorum sensing is a modern and valuable one. Quorum sensing inhibitors act by competition with autoinducers on their receptors. Consequently, they can inhibit biofilm formation, bacterial motility, and virulence factors $[7,22]$. Unfortunately, many of the previously studied quorum sensing inhibitors are clinically toxic. This challenge directed the scientists to find out alternative quorum sensing inhibitors such as FDA approved drugs and plant extracts $[23,24]$. Similar activities have been reported from different plant extracts, among them Vanilla planifolia Andrews showed anti-quorum sensing activity against Chromobacterium violaceum [25]. Similarly, Conocarpus erectus, Bucida buceras, Chamaesyce hypericifolia, Tetrazygia bicolor, Quercus virginiana, Callistemon viminalis, and Syzygium aromaticum extracts exhibited activity against $P$. aeruginosa quorum sensing $[26,27]$. Furthermore, catechin, naringenin, and taxifolin from Combretum albiflorum inhibited quorum sensing in P. aeruginosa and their activities were attributed to decreasing the expression of quorum sensing genes and production of autoinducers $[15,28]$.

In this work, investigation of $S$. tetrasperma stem bark and flower extracts as a quorum sensing inhibitor was carried out. The extracts were found to inhibit PAO1 bacterial growth at a concentration of $40 \mathrm{mg} / \mathrm{mL}$; however, concentrations equivalent to $1 / 4$ and 1/8 MIC did not affect PAO1 viability, therefore, they were used to test the quorum sensing inhibitory effect of stem bark and flower extracts against PAO1. Quorum sensing plays a key role in biofilm formation [29]. The extracts were found to inhibit these kinds of virulence factors at doses lower than MIC. Previous studies of Hibiscus sabdariffa and Moringa oleifera extracts reflected their inhibitory effect against biofilm formation in P. aeruginosa, the latter exhibited similar activity in Staphylococcus aureus and Candida albicans [6,30].

One of the factors that affect biofilm formation is the ability of bacteria to adhere to surfaces which is linked to bacterial motility that is under the control of LasR and rhlR [31]. By targeting those enzymes; the motility is impaired, resulting in formation of weak and dispersible biofilms [32]. In this work, motility impairment was achieved using S. tetrasperma stem bark and flower extracts. In addition, 
P. aeruginosa can invade host tissues by the aid of hydrolytic enzymes as protease and hemolysin [33]. The inhibition of these enzymes represents a good strategy to overcome the spread of bacterial cells in the host [33]. Stem bark and flower extracts inhibited protease and hemolysin activity, and therefore they help in decreasing the spread of bacterial cells. Similar activities were reported from Chamaemelum nobile, Ananas comosus, Musa paradiciaca, Manilkara zapota, Ocimum sanctum, and Lagerstroemia speciosa extracts [34-36].

Molecular docking of main components of the stem bark and flower extracts revealed that their quorum sensing inhibition can be attributed mainly to epicatechin, (epi)catechin-(epi)catechin, $p$-hydroxy benzoyl galloyl glucose, and $p$-hydroxy benzoyl protocatechuic acid glucose from the stem bark extract and caffeoylmalic acid from the flower extract. Previous docking of epicatechin and proanthocyanidin from cranberry on Lasl/LasR system is in agreement with our results [37]. Another study showed that caffeoyl derivatives were found to be the main components of the anti-quorum sensing Burdock root extract [38].

\section{Materials and Methods}

\subsection{Plant Material and Extraction}

The stem bark and flowers (catkins) of Salix tetrasperma were collected during the spring season (30 April, 2018) from the province of Qalubiya, (Banha-Zagazig road, location $30^{\circ} 28^{\prime} 15^{\prime \prime} \mathrm{N} 31^{\circ} 14^{\prime} 50^{\prime \prime} \mathrm{E}$ ), Egypt. Plant identity was verified by Dr. H. Abdel Baset, Professor of Botany, Faculty of Science, Zagazig University, Egypt and voucher specimen were deposited in the Herbarium of Pharmacognosy Department, Faculty of Pharmacy, Zagazig University, Egypt (Voucher specimen no SST-3 and SST-4). The stem bark and flowers were dried in shade and, then, ground into fine powder by an electric mill. Two hundred grams from each of the resulting powders were extracted twice with methanol at room temperature for a period of three days with occasional shaking. The obtained extracts were filtered and concentrated using rotary evaporator at $40{ }^{\circ} \mathrm{C}$ to yield $30 \mathrm{~g}$ and $44 \mathrm{~g}$ of stem bark and flower extracts, respectively. The concentrated extracts were defatted with hexane, frozen at $-20^{\circ} \mathrm{C}$, lyophilized affording 26 and $38 \mathrm{~g}$ stem bark and flower extracts, respectively, and kept at $-20^{\circ} \mathrm{C}$ for chemical and biological investigations.

\subsection{HPLC-MS Analysis}

A ThermoFinnigan LCQ-Duo ion trap mass spectrometer (ThermoElectron Corporation, Waltham, MA, USA) with an ESI source (ThermoQuest Corporation, Austin, TX, USA) was used. A Discovery HS F5 column ( $15 \mathrm{~cm} \times 4.6 \mathrm{~mm}$ ID, $5 \mu \mathrm{m}$ particles) (Sigma-Aldrich Co, Steinheim, Germany) was utilized with the ThermoFinnigan HPLC system. The mobile phase was water and acetonitrile (ACN) (Sigma-Aldrich $\mathrm{GmbH}$, Steinheim, Germany) (0.1\% formic acid each). At $0 \mathrm{~min}$, ACN was $5 \%$, then increased to $30 \%$ over $60 \mathrm{~min}$, and finally to $90 \%$ within the last $30 \mathrm{~min}$. The flow rate was kept at $1 \mathrm{~mL} / \mathrm{min}$ with a 1:1 split before the ESI source. The MS operated in the negative mode as previously reported [39].

\subsection{Media and Chemicals}

Luria-Bertani (LB) agar, LB broth and tryptone were purchased from Lab M Limited (Lancashire, UK). Mueller Hinton agar, Mueller Hinton broth, and tryptone soya agar and tryptone soya broth were obtained from Oxoid (Hampshire, UK). Other chemicals were of pharmaceutical grade. Bacterial strains of Pseudomonas aeruginosa PAO1 were kindly donated by the Department of Microbiology, Faculty of Pharmacy, Mansoura University, Egypt. 


\subsection{Minimum Inhibitory Concentration (MIC) Determination and Subinhibitory Concentration Effect on Bacterial Growth}

The minimum inhibitory concentrations of stem bark and flower extracts were determined using the broth microdilution method (CLSI) [9]. The extracts were two-fold serially diluted in Mueller Hinton broth $(320,160,80,40,20,10,5 \mathrm{mg} / \mathrm{mL})$ and added in a volume of $100 \mu \mathrm{L}$ to the wells of a microtiter plate. PAO1 suspension $(100 \mu \mathrm{L})$ in Mueller Hinton broth with $1 \times 10^{6} \mathrm{CFU} / \mathrm{mL}$ were added to each well. The PAO1-S. tetrasperma extract mixtures were incubated for $20 \mathrm{~h}$ at $37^{\circ} \mathrm{C}$, the minimum inhibitory concentration was defined as the lowest concentration without visible growth. Doses of $1 / 4$ and 1/8 MIC were used to determine the effect of different extracts on growth of PAO1 as described with little modifications [40]. PAO1 culture in LB broth was inoculated overnight at $37^{\circ} \mathrm{C}$ with and without the tested extracts. The turbidity of the treated and untreated cultures was determined by Biotek Spectrofluorimeter (Biotek, Winooski, VT, USA) at $600 \mathrm{~nm}$.

\subsection{Measurement of Biofilm Inhibition}

The PAO1 cells were allowed to grow in TSB overnight at an optical density adjusted to OD600 $=1$. The adjusted bacterial culture was inoculated with fresh media in $50 \mathrm{~mL}$ centrifuge tubes with sterilized cover slips in the presence and absence of $1 / 4$ and $1 / 8 \mathrm{MIC}$ of the investigated extracts. The inoculation took place for $16 \mathrm{~h}$ at $37^{\circ} \mathrm{C}$. After washing the cover slips with phosphate-buffered saline, the attached biofilms were stained with $1 \%$ crystal violet and microscopically examined using oil immersion lens (magnification power $=100 \times)$ [35].

\subsection{Measurement of Swimming and Swarming Motilities}

The effect of the bark and flower extracts on swimming and swarming motilities was studied as described by Rashid and Kornberg with few modifications [41,42]. With respect to the swimming assay, $1 \%$ tryptone, $0.5 \%$ sodium chloride, and $0.3 \%$ agar in the presence and absence of $1 / 4$ and $1 / 8$ MIC of the extracts were used to prepare swimming agar plates. PAO1 was cultured in tryptone broth overnight, and then diluted. Five micro-Liters of the diluted culture were stabbed into the center of the agar plates and kept at $37^{\circ} \mathrm{C}$ for $24 \mathrm{~h}$ followed by measurement of the swimming zones. Concerning the swarming assay, another $5 \mu \mathrm{L}$ from PAO1 overnight culture were added onto the surface of the center of dried LB swarming agar plates (1.5\%) with and without $1 / 4$ and 1/8 MIC of the extracts. After an overnight incubation of the prepared plates at $37^{\circ} \mathrm{C}$, diameters of the swarming zones were measured in $\mathrm{mm}$. Pieces from the center and edges of LB swarming agar that contain vegetative and swarmer cells, respectively, were aseptically cut. The cells were cleaned from the agar pieces using phosphate buffered saline, then stained with safranine, and examined under the oil immersions lens.

\subsection{Measurement of Protease Inhibition}

Skim milk agar method was followed to evaluate the inhibition of protease activity by the different extracts [43]. PAO1 cells were incubated in LB broth in the presence and absence of the tested extracts (1/4 and 1/8 MIC) overnight. The cultures were centrifuged at 10,000 rpm for 15 min to obtain supernatants from which $100 \mu \mathrm{L}$ were added in the wells of $5 \%$ skim milk agar plates and incubated at $37^{\circ} \mathrm{C}$ overnight. The proteolytic activity was determined by measurement of clear zones around the wells.

\subsection{Measurement of Hemolysis Inhibition}

The method of Rossignol et al. was followed to evaluate the anti-hemolytic activity of stem bark and flower extracts [44]. The supernatants of PAO1 cultures (treated and untreated with 1/4 and 1/8 MIC of the tested extracts) were used in this experiment. Briefly, $500 \mu \mathrm{L}$ of these supernatants were added to $2 \%$ fresh erythrocyte saline suspension $(700 \mu \mathrm{L})$, the mixtures were incubated at $37^{\circ} \mathrm{C}$ for 2 $\mathrm{h}$ after which the hemoglobin was released by lysis of the erythrocytes, and then the lysed mixtures 
were centrifuged at $2500 \mathrm{rpm}$ and $4{ }^{\circ} \mathrm{C}$ for $5 \mathrm{~min}$. The activity was determined by measurement of absorbance at $540 \mathrm{~nm}$ relative to positive and negative controls that were prepared by incubating the erythrocytes in presence and absence of $0.1 \%$ SDS, respectively.

Percentage of hemolysis was determined using the equation: $\%$ hemolysis $=[X-B / T-B] \times 100$, where $\mathrm{X}$ is samples (treated and untreated), $\mathrm{B}$ : is negative control, and $\mathrm{T}$ is positive control [9].

\subsection{Molecular Modelling Study}

Virtual screening of the identified compounds was done on P. aeruginosa LasR ligand-binding domain (PDB ID 2UV0, $1.8 \mathrm{~A}^{\circ}$ [45]), RhlG/NADP active site (PDB ID 2B4Q, $2.3 \mathrm{~A}^{\circ}$ [46]), and PqsR active domain (PDB ID 4JVD, $2.59 \mathrm{~A}^{\circ}$ [47]) downloaded from protein data bank (www.pdb.org) representing the Lasl/LasR system, rhll/rhlR system, and PQS/MvfR system involved in the quorum sensing systems, respectively, using Discovery Studio 4.5 (Accelrys Inc., San Diego, USA). C-docker protocol was used and docking was performed in a similar manner as a previously described method adopting the rule-based ionization method to detect the possible influence of ionization of various active groups on the interaction of the compound at the active pocket of the enzyme [48,49]. The free binding energies were calculated in $\mathrm{kcal} / \mathrm{mol}$.

\section{Conclusions}

A total of 38 compounds were identified by LC-MS analysis of Salix tetrasperma stem bark extract. Screening of this extract together with the flower extract clarifies their importance in overcoming bacterial resistance by acting as quorum sensing inhibitors. The extracts were found to impair virulence of Pseudomonas aeruginosa by reducing its swimming and swarming motilities and decreasing its proteolytic and hemolytic activities. The results were confirmed through a molecular docking study of the extracts' constituents against Lasl/LasR, rhll/rhlR, and PQS/MvfR systems that control the bacterial virulence.

Supplementary Materials: LC-MS/MS spectra of some selected compounds from the bark extract are available online.

Author Contributions: I.M. and M.S. performed extraction and chemical characterization; H.A.A. performed the microbiological experiments; M.L.A. performed molecular docking; I.M., A.Y., and H.A.A. analyzed the data; I.M., M.L.A., and M.S. wrote the manuscript; I.M., H.A.A., A.M.E.-S., M.W. and M.S. designed and conceived the project. All authors have read and agreed to the published version of the manuscript.

Funding: The research was funded by Deutsche Forschungsgemeinschaft and Ruprecht-Karls-Universität Heidelberg within the funding program Open Access Publishing.

Acknowledgments: Authors are greatly thankful to Ali Osman, Department of Biochemistry, Faculty of Agriculture, Zagazig University for lyophilization of the extracts.

Conflicts of Interest: The authors declare no conflict of interest.

\section{References}

1. Mashhady, M.A.; Abkhoo, J.; Jahani, S.; Abyar, S.; Khosravani, F. Inhibitory effects of plant extracts on Pseudomonas aeruginosa biofilm formation. Life 2016, 3, e38199. [CrossRef]

2. Fletcher, J.; Leach, J.E.; Eversole, K.; Tauxe, R. Human pathogens on plants: Designing a multidisciplinary strategy for research. Phytopathology 2013, 103, 306-315. [CrossRef] [PubMed]

3. Walker, T.S.; Bais, H.P.; Déziel, E.; Schweizer, H.P.; Rahme, L.G.; Fall, R.; Vivanco, J.M. Pseudomonas aeruginosa-plant root interactions. Pathogenicity, biofilm formation, and root exudation. Plant Physiol. 2004, 134, 320-331. [CrossRef] [PubMed]

4. Dietrich, L.E.; Price-Whelan, A.; Petersen, A.; Whiteley, M.; Newman, D.K. The phenazine pyocyanin is a terminal signalling factor in the quorum sensing network of Pseudomonas aeruginosa. Mol. Microbiol. 2006, 61, 1308-1321. [CrossRef]

5. Bodey, G.P.; Bolivar, R.; Fainstein, V.; Jadeja, L. Infections caused by Pseudomonas aeruginosa. Rev. Infect. Dis. 1983, 5, 279-313. [CrossRef] 
6. Abbas, H.A.; Abdo, I.M.; Moustafa, M.Z. In vitro antibacterial and antibiofilm activities of Hibiscus sabdariffa L. Extract and apple vinegar against bacteria isolated from diabetic foot infections. Res. J. Pharm. Technol. 2014, 7, 131-136.

7. Hentzer, M.; Wu, H.; Andersen, J.B.; Riedel, K.; Rasmussen, T.B.; Bagge, N.; Kumar, N.; Schembri, M.A.; Song, Z.; Kristoffersen, P. Attenuation of Pseudomonas aeruginosa virulence by quorum sensing inhibitors. EMBO J. 2003, 22, 3803-3815. [CrossRef]

8. Alavi, M.; Karimi, N.; Valadbeigi, T. Antibacterial, antibiofilm, antiquorum sensing, antimotility, and antioxidant activities of green fabricated $\mathrm{Ag}, \mathrm{Cu}, \mathrm{TiO} 2, \mathrm{ZnO}$, and $\mathrm{Fe} 3 \mathrm{O} 4 \mathrm{NPs}$ via Protoparmeliopsis muralis lichen aqueous extract against multi-drug-resistant bacteria. ACS Biomater. Sci. Eng. 2019, 5, 4228-4243. [CrossRef]

9. Abbas, H.A.; Elsherbini, A.M.; Shaldam, M.A. Repurposing metformin as a quorum sensing inhibitor in Pseudomonas aeruginosa. Afr. Health Sci. 2017, 17, 808-819. [CrossRef]

10. Pesci, E.C.; Pearson, J.P.; Seed, P.C.; Iglewski, B.H. Regulation of las and rhl quorum sensing in Pseudomonas aeruginosa. J. Bacteriol. 1997, 179, 3127-3132. [CrossRef]

11. Whiteley, M.; Lee, K.M.; Greenberg, E. Identification of genes controlled by quorum sensing in Pseudomonas aeruginosa. Proc. Natl. Acad. Sci. USA 1999, 96, 13904-13909. [CrossRef] [PubMed]

12. Miller, M.B.; Bassler, B.L. Quorum sensing in bacteria. Annu. Rev. Microbiol. 2001, 55, 165-199. [CrossRef] [PubMed]

13. Abbas, H.A.M.; Soliman, W.E.E.; Shaldam, M.A. Perturbation of quorum sensing in Pseudomonas aeruginosa by febuxostat. Adv. Microbiol. 2018, 8, 650. [CrossRef]

14. Kumar, N.V.; Murthy, P.S.; Manjunatha, J.; Bettadaiah, B. Synthesis and quorum sensing inhibitory activity of key phenolic compounds of ginger and their derivatives. Food Chem. 2014, 159, 451-457. [CrossRef] [PubMed]

15. Vandeputte, O.M.; Kiendrebeogo, M.; Rajaonson, S.; Diallo, B.; Mol, A.; El Jaziri, M.; Baucher, M. Identification of catechin as one of the flavonoids from Combretum albiflorum bark extract that reduces the production of quorum-sensing-controlled virulence factors in Pseudomonas aeruginosa pao1. Appl. Environ. Microbiol. 2010, 76, 243-253. [CrossRef] [PubMed]

16. Enayat, S.; Banerjee, S. Comparative antioxidant activity of extracts from leaves, bark and catkins of Salix aegyptiaca sp. Food Chem. 2009, 116, 23-28. [CrossRef]

17. Hussain, H.; Badawy, A.; Elshazly, A.; Elsayed, A.; Krohn, K.; Riaz, M.; Schulz, B. Chemical constituents and antimicrobial activity of Salix subserrata. Rec. Nat. Prod. 2011, 5, 133.

18. Van Wyk, B.E.; Wink, M. Phytomedicines, Herbal Drugs \& Plant Poisons; Briza Publications: Pretoria, South Africa, 2015.

19. Sobeh, M.; Mahmoud, M.F.; Rezq, S.; Alsemeh, A.E.; Sabry, O.M.; Mostafa, I.; Abdelfattah, M.A.; Ait El-Allem, K.; El-Shazly, A.M.; Yasri, A. Salix tetrasperma roxb. extract alleviates neuropathic pain in rats via modulation of the nf-kb/tnf- $\alpha /$ nox/inos pathway. Antioxidants 2019, 8, 482. [CrossRef]

20. El-Shazly, A.; El-Sayed, A.; Fikrey, E. Bioactive secondary metabolites from Salix tetrasperma Roxb. Z. Naturforsch. C. 2012, 67, 353-359. [CrossRef]

21. Tawfeek, N.; Sobeh, M.; Hamdan, D.I.; Farrag, N.; Roxo, M.; El-Shazly, A.M.; Wink, M. Phenolic compounds from Populus alba L. and Salix subserrata Willd. (Salicaceae) counteract oxidative stress in caenorhabditis elegans. Molecules 2019, 24, 1999. [CrossRef]

22. Zhao, T.; Liu, Y. N-acetylcysteine inhibit biofilms produced by Pseudomonas aeruginosa. BMC Microbiol. 2010, 10, 140. [CrossRef] [PubMed]

23. Galloway, W.R.; Hodgkinson, J.T.; Bowden, S.; Welch, M.; Spring, D.R. Applications of small molecule activators and inhibitors of quorum sensing in gram-negative bacteria. Trends Microbiol. 2012, 20, 449-458. [CrossRef] [PubMed]

24. Abbas, H.A.; Shaldam, M.A. Glyceryl trinitrate is a novel inhibitor of quorum sensing in Pseudomonas aeruginosa. Afr. Health Sci. 2016, 16, 1109-1117. [CrossRef] [PubMed]

25. Choo, J.; Rukayadi, Y.; Hwang, J.K. Inhibition of bacterial quorum sensing by vanilla extract. Lett. Appl. Microbiol. 2006, 42, 637-641. [CrossRef]

26. Adonizio, A.; Kong, K.-F.; Mathee, K. Inhibition of quorum sensing-controlled virulence factor production in Pseudomonas aeruginosa by south florida plant extracts. Antimicrob. Agents Chemother. 2008, 52, 198-203. [CrossRef] [PubMed] 
27. Krishnan, T.; Yin, W.F.; Chan, K.G. Inhibition of quorum sensing-controlled virulence factor production in Pseudomonas aeruginosa pao1 by ayurveda spice clove (Syzygium aromaticum) bud extract. Sensors 2012, 12, 4016-4030. [CrossRef] [PubMed]

28. Vandeputte, O.M.; Kiendrebeogo, M.; Rasamiravaka, T.; Stevigny, C.; Duez, P.; Rajaonson, S.; Diallo, B.; Mol, A.; Baucher, M.; El Jaziri, M. The flavanone naringenin reduces the production of quorum sensing-controlled virulence factors in Pseudomonas aeruginosa pao1. Microbiology 2011, 157, 2120-2132. [CrossRef]

29. Kirisits, M.J.; Parsek, M.R. Does Pseudomonas aeruginosa use intercellular signalling to build biofilm communities? Cell. Microbiol. 2006, 8, 1841-1849. [CrossRef]

30. Onsare, J.; Arora, D. Antibiofilm potential of flavonoids extracted from Moringa oleifera seed coat against Staphylococcus aureus, Pseudomonas aeruginosa and Candida albicans. J. Appl. Microbiol. 2015, 118, 313-325. [CrossRef]

31. Glessner, A.; Smith, R.S.; Iglewski, B.H.; Robinson, J.B. Roles of Pseudomonas aeruginosa las and rhl quorum-sensing systems in control of twitching motility. J. Bacteriol. 1999, 181, 1623-1629. [CrossRef]

32. Heydorn, A.; Ersbøll, B.; Kato, J.; Hentzer, M.; Parsek, M.R.; Tolker-Nielsen, T.; Givskov, M.; Molin, S. Statistical analysis of Pseudomonas aeruginosa biofilm development: Impact of mutations in genes involved in twitching motility, cell-to-cell signaling, and stationary-phase sigma factor expression. Appl. Environ. Microbiol. 2002, 68, 2008-2017. [CrossRef] [PubMed]

33. Gupta, R.K.; Setia, S.; Harjai, K. Expression of quorum sensing and virulence factors are interlinked in Pseudomonas aeruginosa: An in vitro approach. Am. J. Biomed. Sci. 2011, 3, 116-125. [CrossRef]

34. Kazemian, H.; Ghafourian, S.; Heidari, H.; Amiri, P.; Yamchi, J.K.; Shavalipour, A.; Houri, H.; Maleki, A.; Sadeghifard, N. Antibacterial, anti-swarming and anti-biofilm formation activities of Chamaemelum nobile against Pseudomonas aeruginosa. Rev. Soc. Bras. Med. Trop. 2015, 48, 432-436. [CrossRef] [PubMed]

35. Musthafa, K.S.; Ravi, A.V.; Annapoorani, A.; Packiavathy, I.S.V.; Pandian, S.K. Evaluation of anti-quorum-sensing activity of edible plants and fruits through inhibition of the n-acyl-homoserine lactone system in Chromobacterium violaceum and Pseudomonas aeruginosa. Chemotherapy 2010, 56, 333-339. [CrossRef] [PubMed]

36. Singh, B.N.; Singh, H.; Singh, A.; Singh, B.R.; Mishra, A.; Nautiyal, C. Lagerstroemia speciosa fruit extract modulates quorum sensing-controlled virulence factor production and biofilm formation in Pseudomonas aeruginosa. Microbiology 2012, 158, 529-538. [CrossRef] [PubMed]

37. Maisuria, V.B.; Lopez-de Los Santos, Y.; Tufenkji, N.; Déziel, E. Cranberry-derived proanthocyanidins impair virulence and inhibit quorum sensing of Pseudomonas aeruginosa. Sci. Rep. 2016, 6, 30169. [CrossRef] [PubMed]

38. Rajasekharan, S.K.; Ramesh, S.; Bakkiyaraj, D.; Elangomathavan, R.; Kamalanathan, C. Burdock root extracts limit quorum-sensing-controlled phenotypes and biofilm architecture in major urinary tract pathogens. Urolithiasis 2015, 43, 29-40. [CrossRef]

39. Sobeh, M.; Hassan, S.A.; El Raey, M.A.; Khalil, W.A.; Hassan, M.A.; Wink, M. Polyphenolics from Albizia harveyi exhibit antioxidant activities and counteract oxidative damage and ultra-structural changes of cryopreserved bull semen. Molecules 2017, 22, 1993. [CrossRef]

40. Nalca, Y.; Jänsch, L.; Bredenbruch, F.; Geffers, R.; Buer, J.; Häussler, S. Quorum-sensing antagonistic activities of azithromycin in Pseudomonas aeruginosa pao1: A global approach. Antimicrob. Agents Chemother. 2006, 50, 1680-1688. [CrossRef]

41. Rashid, M.H.; Kornberg, A. Inorganic polyphosphate is needed for swimming, swarming, and twitching motilities of Pseudomonas aeruginosa. Proc. Natl. Acad. Sci. USA 2000, 97, 4885-4890. [CrossRef]

42. Abbas, H.A. Antibacterial, anti-swarming and antibiofilm activities of local Egyptian clover honey against Proteus mirabilis isolated from diabetic foot infection. Asian, J. Pharm. Res. 2013, 3, 114-117.

43. Vijayaraghavan, P.; Vincent, S.G.P. A simple method for the detection of protease activity on agar plates using bromocresolgreen dye. J. Biochem. Technol. 2013, 4, 628-630.

44. Rossignol, G.; Merieau, A.; Guerillon, J.; Veron, W.; Lesouhaitier, O.; Feuilloley, M.G.; Orange, N. Involvement of a phospholipase $\mathrm{C}$ in the hemolytic activity of a clinical strain of Pseudomonas fluorescens. BMC Microbiol. 2008, 8, 189. [CrossRef] [PubMed]

45. Bottomley, M.J.; Muraglia, E.; Bazzo, R.; Carfi, A. Molecular insights into quorum sensing in the human pathogen Pseudomonas aeruginosa from the structure of the virulence regulator LasR bound to its autoinducer. J. Biol. Chem. 2007, 282, 13592-13600. [CrossRef] 
46. Miller, D.J.; Zhang, Y.M.; Rock, C.O.; White, S.W. Structure of RhlG, an Essential beta-Ketoacyl Reductase in the Rhamnolipid Biosynthetic Pathway of Pseudomonas aeruginosa. J. Biol. Chem. 2006, 281, 18025-18032. [CrossRef]

47. Ilangovan, A.; Fletcher, M.; Rampioni, G.; Pustelny, C.; Rumbaugh, K.; Heeb, S.; Camara, M.; Truman, A.; Chhabra, S.R.; Emsley, J.; et al. Structural basis for native agonist and synthetic inhibitor recognition by the Pseudomonas aeruginosa quorum sensing regulator PqsR (MvfR). PLoS Pathog. 2013, 9, e1003508. [CrossRef]

48. Youssef, F.S.; Ashour, M.L.; Sobeh, M.; El-Beshbishy, H.A.; Singab, A.N.; Wink, M. Eremophila maculata-isolation of a rare naturally-occurring lignan glycoside and the hepatoprotective activity of the leaf extract. Phytomedicine 2016, 23, 1484-1493. [CrossRef]

49. Ashour, M.L.; Youssef, F.S.; Gad, H.A.; Wink, M. Inhibition of cytochrome p450 (cyp3A4) activity by extracts from 57 plants used in Traditional Chinese Medicine (TCM). Pharmacogn. Mag. 2017, 13, 300.

Sample Availability: Samples of the plant materials are available from the authors.

(C) 2020 by the authors. Licensee MDPI, Basel, Switzerland. This article is an open access article distributed under the terms and conditions of the Creative Commons Attribution (CC BY) license (http://creativecommons.org/licenses/by/4.0/). 